\section{Parts of phycology}

\section{Howard Pearson}

Introduction to the Algae, 2nd Edn.

By Harold C. Bold and Michael J.

Wynne.

Prentice-Hall: 1985. Pp.720. \$53.95,

\section{£49.15.}

UNDERGRADUATES requiring an up-todate text on the algae, which concentrates on cell structure, reproduction and classification, will benefit greatly from this factual, well-written, concise and wellpresented book. Researchers who spend most of their time "torturing" the physiology and biochemistry out of algal cells, but want to know how their "tame" species fit into the greater scheme of things, will also profit from reading it.

The book was not written to cover all aspects of modern phycology (a point acknowledged by the authors), but to complement other texts on algal ecology, physiology, biochemistry and genetics. In this respect it is not adequate for an introductory phycology course, or for students attracted primarily to the algae by an interest in their potential biotechnological applications.

This second edition retains the format of the first, with an outstanding introductory chapter (worthy in itself of publication as a booklet) preceding accounts of the algae division by division. The blue-green algae are included, as are new sections on Prochloron and algae of uncertain affinity. There are also other minor additions and changes to some of the keys. Mercifully, Bold and Wynne have dropped the unnecessary "phyco" from the algal division names so that, for example, the Chlorophycophyta revert to being the Chlorophyta. The glossary of terms is retained and aids the use of the simple-tofollow keys to the genera of each division, while the updated reference section provides a good lead into further reading. However, I regret the deletion in this edition of the very useful appendix on culture methods as the basic information greatly helps those embarking on the culture of algae.

In all this is an excellent book, full of useful pieces of information. The many photographs and line drawings complement the text and merit special praise. Bold and Wynne have managed to bring alive what even to many dedicated phycologists is a less than stimulating, albeit essential, area of the subject.

Howard Pearson is a Lecturer in the Department of Botany at the University of Liverpool.

nuclear, chloroplast and mitochondrial genomes. The chapter on hormonal and environmental factors affecting gene expression reflects our level of ignorance in this important area, and is disappointing in its lack of coverage of some of the better understood aspects of the responses of plants to stress, such as heat shock and anaerobiosis. The accounts of plantbacterial interaction in nitrogen fixation and in the natural gene transfer system of the Agrobacterium Ti plasmid are excellent introductions to each subject, as is that describing plant viruses, and lead logically into a final discussion of the prospects for genetic engineering of plants. This chapter illustrates the fact that although it is possible to list some of the goals for plant improvement, we still have little idea of the identity or mode of regulation of the genes we might modify or transfer.

The text contains errors, but this failing is partly compensated for by the up-to-date bibliography which allows ready access to original papers. The authors have produced a book which provides a solid basis for undergraduate courses on plant molecular biology, and which will also be useful to the inquisitive postgraduate and the informed entrepreneur requiring scientific background on the investment potential of plant biotechnology.

C.J. Leaver is Reader in Plant Molecular Biology and S.M. Smith is Lecturer in Plant Biotechnology in the Department of Botany, University of Edinburgh.

\section{Longman Science Texts}

\section{Available now. . .}

The Planning and Management of Environmentally Sensitive Areas Paul FJ Eagles

Themes in Resource Management Series Essentially a text on applied ecology with specific reference to environmental planning, introckis the Enviro present an integrated. (ESAs) Destined to in the field.

Paper 224pp 0582300746

(1984

$£ 7.95$ net

\section{Allas of Invertebrate Macrofossils}

Edited by John Murray

This atlas is intended as a field and laboratory uide to the recognition and indentification of (t) give as waustive coverag possible rather than to 1,500 photographs of specimens from all parts of the world.

Paper 224pp 058230099

$£ 13.95$ net

Reconstructing Quaternary Environments $\mathrm{J} J$ Lowe and M J C Walker

This original and broad-ranging contribution to This

disciplined aporoach to the subject and will be disciplined approach to the subject and will be in a variety of fieds incudints and professionals a variety of fields including geology, physical and zoology.

0582300703

cember 1984

$£ 12.95$ net

Late Quaternary Environments of the Soviet Union

A A Velichko

A collection of 30 papers on Late Quaternary environmental history by Soviet specialists in the earth sciences, palaeoecology and palaeoclimatology. Much of this research has only been accomplished in the last 30 years aring hook a source thats

Cased 488pp 0582301254

Published February 1985

Forthcoming....

Mathematical Methods for Scientists and Engineers

G Stephenson

A collection of fully worked problems covering alf the important topics met in ancillary undergraduate mathematics courses. This book will greatly facilitate the understanding of mathematical techniques and provide uniquely effective

Paper 160pp 058244684

Published March 1985

$\$ 4.95$ net

Henderson's Dictionary of Biological Terms Ninth edition

Sandra B Hoimes

This famous dictionary, available in paperback for the first time, clearly defines about 22,500 erms encountered in the field. All subject are covered including biochemistry, botany, genetics, microbiology and zoology. It remains the most comprehensive dictionary of biological terms in print

Cased 522pp 0582462428

Published $1969 \quad$ \&12.95 net

Paper 522po 0582447593

Published May 1985 \&4.50 net

These thies are avallable from your bookseller. In ceses of difficulty or for urther information pleateo contact Doborah Burtenahew, Longmen Group td, Longman House, Burnt Mill, Hartow, seax CIn20 2JE.

Longman

Circle No.16 on Reader Service Card. 